\title{
From research to action: enhancing crop yield through wild pollinators
}

\author{
Lucas A Garibaldi ${ }^{1 *}$, Luísa G Carvalheiro ${ }^{2,3}$, Sara D Leonhardt ${ }^{4}$, Marcelo A Aizen ${ }^{5}$, Brett R Blaauw ${ }^{6}$, \\ Rufus Isaacs ${ }^{6}$, Michael Kuhlmann ${ }^{7}$, David Kleijn ${ }^{8,9}$, Alexandra M Klein ${ }^{10}$, Claire Kremen ${ }^{11}$, Lora Morandin ${ }^{11}$, \\ Jeroen Scheper ${ }^{8}$, and Rachael Winfree ${ }^{12}$
}

Recent evidence highlights the value of wild-insect species richness and abundance for crop pollination worldwide. Yet, deliberate physical importation of single species (eg European honey bees) into crop fields for pollination remains the mainstream management approach, and implementation of practices to enhance crop yield (production per area) through wild insects is only just beginning. With few exceptions, studies measuring the impacts of pollinator-supporting practices on wild-insect richness and pollination service success - particularly in relation to long-term crop yield and economic profit - are rare. Here, we provide a general framework and examples of approaches for enhancing pollinator richness and abundance, quantity and quality of pollen on stigmas, crop yield, and farmers' profit, including some benefits detected only through long-term monitoring. We argue for integrating the promotion of wild-insect species richness with single-species management to benefit farmers and society.

Front Ecol Environ 2014; 12(8): 439-447, doi:10.1890/130330 (published online 23 Sep 2014)

$F_{\mathrm{r} e m}^{2}$ armland covers more than 35\% of Earth's ice-free terrestrial area, and agriculture is expanding and intensifying in many regions to meet the growing demands of human populations (FAO 2013). This trend threatens biodiversity and the ecosystem services on which agriculture depends, including crop pollination (Garibaldi et al. 2011a). Indeed, recent reviews have highlighted how multiple anthropogenic pressures lead to a decline in wild pollinators such as bees, flies, beetles, and butterflies (Vanbergen and the Insect Pollinators Initiative 2013). However, practices to enhance wild pollinators in agroecosystems are still in development (Kremen et al. 2007;

\section{In a nutshell:}

- Farms with greater numbers of wild-insect species (richness) exhibit higher abundance of flower visitors and enhanced crop pollination; however, the effectiveness of practices to enhance both pollinator richness and crop yield is unclear

- We offer examples of practices (eg wildflower plantings) that promote pollinator "success" - including species richness and abundance - and discuss where and when such methods are expected to be effective for crop pollination

- Our review provides a general framework for increasing wildinsect pollinator richness and abundance for improved pollination quality and quantity

- Introduction of such methods to complement current singlespecies management (eg the use of European honey bees) can lead to higher and more stable crop yields

\footnotetext{
${ }^{1}$ Sede Andina, Universidad Nacional de Río Negro and Consejo Nacional de Investigaciones Científicas y Técnicas (CONICET), San Carlos de Bariloche, Argentina *(lgaribaldi@unm.edu.ar); ${ }^{2}$ School of Biology, University of Leeds, Leeds, UK; ${ }^{3}$ Naturalis Biodiversity Center, Leiden, The Netherlands; continued on p 447
}

FAO 2008; Menz et al. 2011), and considerable uncertainty remains regarding their effects on crop yield (production per area) and farmers' profits. Here we review recent research on the topic, including the impacts of certain practices on wild pollinators, crop pollination, yield, and profits (WebFigure 1). We focus on practices that enhance the carrying capacity of habitats for wildinsect assemblages that may then provide crop pollination services; practices to conserve or manage a particular pollinator species are outside our scope although they have received attention elsewhere (eg Bohart 1972). We offer general science-based advice to land managers and policy makers and highlight knowledge gaps. Throughout, we emphasize the need to consider population-level processes, rather than just short-term behavioral responses of pollinators to floral resources.

\section{Diverse assemblages of wild insects improve pollination}

Plant-pollinator interactions are typically very general, with many pollinators being rewarded with pollen, nectar, or other resources from several plant species (WebPanel 1), and with most angiosperms being pollinated by multiple insect species (Waser et al. 1996). Humans benefit from this generalized nature of pollination systems, as exotic crops brought far from their ancestral ranges can find effective pollinators within native insect assemblages (Garibaldi et al. 2013). Accordingly, a synthesis of 600 fields from 41 crop systems showed that only two of the 68 most frequent pollinators globally were specialist species: the weevil Elaeidobius kamerunicus pollinating oil palm and the squash-bee Peponapis pruinosa pollinating pumpkin (Table S2 in Garibaldi et al. 2013). 


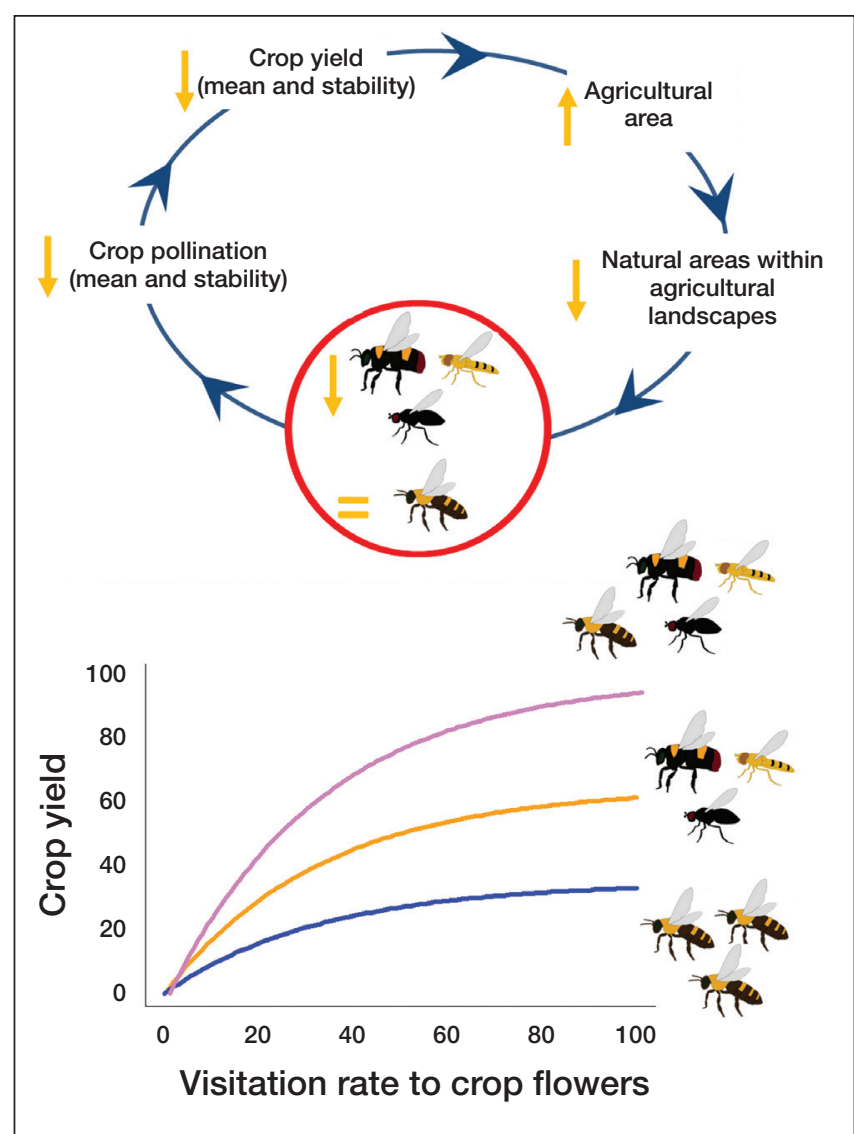

Figure 1. Cycle of wild pollinator decline in agricultural systems and global consequences. Pollen limitation hinders yield (metric tons per hectare) of pollinator-dependent crops, decreasing temporal stability of production and promoting compensatory land conversion to agriculture at the expense of (semi-)natural areas. These land-use changes decrease wild pollinator richness/ abundance and crop pollination, but do not affect honey bee abundance. However, increasing the abundance of only honey bees does not compensate for the pollination losses from fewer wild insects (see references in main text). Drawings courtesy of A Hudewenz. Note that both variables (crop yield and visitation rate) in the lower panel are expressed in relative terms, where 0 and 100 are the minimum and maximum values, respectively.

Because of differences in species functional traits, greater pollinator richness can lead to foraging complementarity or synergy, improving the quantity and quality of pollination (Blüthgen and Klein 2011) and therefore increasing both the proportion of flowers setting fruits (or seeds) and product quality (eg fruit size and shape). Across crop species, insects with contrasting mouthpart (eg tongue) lengths may be needed for the pollination of flowers not only with easily accessible rewards but also with rewards hidden at the bottom of a tubular corolla (Fontaine et al. 2006). Within a crop species, social and solitary bees visited flowering radish plants at different times of day, suggesting temporal complementarity among these pollinator groups (Albrecht et al. 2012). Flower visiting behavior also differs among pollinators of different body sizes, and visits by a range of differently sized pollinator species increase pumpkin pollination (Hoehn et al. 2008). In addition to functional traits, interspecific differences in response traits to climate and land-use change (Winfree et al. 2009; Williams et al. 2010) can increase resilience of pollination services (Brittain et al. 2013).

The role of diverse assemblages of wild insects in crop pollination is also evident from recent global analyses. Worldwide, incomplete and variable animal pollen delivery decreases the growth and stability of yields for pollinator-dependent crops (Garibaldi et al. 2011a). This lower yield growth has been compensated for by greater land cultivation to sustain production growth (Figure 1). The consequent reduction in (semi-)natural areas within agricultural landscapes decreases the richness and abundance of wild pollinators, including bees, syrphid flies, and butterflies (Williams et al. 2010; Winfree et al. 2011a), further diminishing crop pollination (Garibaldi et al. 2011b). A possible solution to this "vicious cycle" is to increase pollinator abundance through single-species management, most commonly European honey bees (Apis mellifera), which are not greatly affected by isolation from natural areas (Winfree et al. 2009; Garibaldi et al. 2011b). However, increasing the abundance of one species may complement but not replace the pollination services provided by diverse assemblages of wild insects, and wild insects pollinate some crops more efficiently than honey bees (Garibaldi et al. 2013). Moreover, during the past 50 years, the fraction of animal-pollinatordependent agriculture and the number of managed honey bee hives have increased $300 \%$ and $45 \%$, respectively, and honey bees have suffered from major health problems such as colony collapse disorder (Aizen and Harder 2009). All of these factors point to the potential benefit of practices that boost the species richness and abundance of wild pollinators. Indeed, richness and visitation rate (a proxy for abundance) of wild pollinators are strongly correlated across agricultural fields globally (Garibaldi et al. 2013). Therefore, practices that enhance habitats to promote species richness are also expected to improve the aggregate abundance of pollinators, and vice versa (WebFigure 1).

\section{Off-field practices}

Below we describe practices that diversify and improve the abundance of resources for wild insects (WebPanel 1) outside the crop field, without affecting crop management. Practices are ranked from less-to-more required area, with practices covering less area likely to be less costly (WebTable 1).

Nesting resources - such as reed internodes (stem segment between nodes) and muddy spots for cavity nesters, and bare ground for soil nesters - can be enhanced at crop field edges without affecting much of the crop area. Although providing such resources can promote the recruitment of certain bee species (Steffan-Dewenter and 
Schiele 2008), evidence of its effects on crop yield is lacking (WebTable 1).

Hedgerows and flower strips are woody or herbaceous vegetation, respectively, planted at the edge of a crop field, and generally covering only a small area. If appropriate plant species are chosen and adequately managed through time (eg proper sowing depth, mowing of perennials), hedgerows and flower strips can provide suitable food and nesting resources for, and enhance species richness and abundance of, bees and syrphid flies (Figure 2). These practices also enhance pollinators in adjacent fields - rather than simply concentrating pollinators at dense flower-rich regions (Figure 2) - and therefore increase crop yield (WebTable 1). Regional programs that augment the quality and availability of seeds from native flowering plants are important for the success of these practices (Isaacs et al. 2009).

Conserving or restoring (semi-)natural areas within landscapes dominated by crops often provides habitat for wild pollinator populations (Figure 3; Garibaldi et al. 2011b; Winfree et al. 2011a). In addition, pollinators depend on various types of resources (WebFigure 2), which are difficult to provide in ways other than by enhancing natural areas. Consequently, these areas also enhance pollination services for nearby crops (WebTable 1).

Enhancing farmland heterogeneity (richness of habitats) increases pollinator richness because plant species provide complementary resources over time and space, and insect species use different resource combinations (Blüthgen and Klein 2011; Kremen and Miles 2012; Shackelford et al. 2013). Also, insects usually require resources for periods longer than crop flowering (Mandelik et al. 2012). In fact, a synthesis of 605 fields from 39 crop systems in different biomes found that diversity of habitats (mixed crop types, presence of hedgerows and flower strips) within 4 ha enhanced bee abundance by $76 \%$ as compared with bee abundance in monoculture fields (Kennedy et al. 2013).

Smaller crop fields increase land-use heterogeneity, and also benefit pollinators because most species forage at distances less than $1 \mathrm{~km}$ from their nests (Zurbuchen et al. $2010 \mathrm{~b}, \mathrm{a})$. Thus, crops in small fields are more likely to benefit from pollinator enhancements such as nearby field margins and hedgerows (Figure 2). Indeed, pollinator richness, visitation rate, and the proportion of flowers setting fruits (or seeds) decreased by 34\%, 27\%, and 16\%, respectively, at $1 \mathrm{~km}$ from (semi-)natural areas across 29 studies worldwide (Garibaldi et al. 2011b).

\section{On-field practices}

In contrast to off-field methods that can be ordered from smaller to larger scale (costs), on-field practices are all applied at a similar spatial scale, ie that of the crop field. Here we discuss practices that (1) reduce the use of insecticides and machinery, (2) enhance the richness of flowering plants, and (3) require greater effort because of

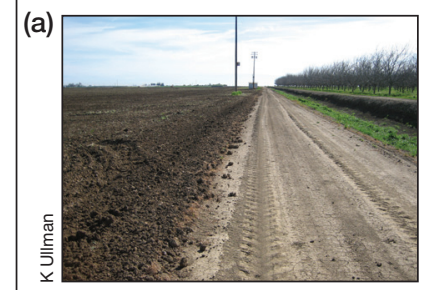

(c)

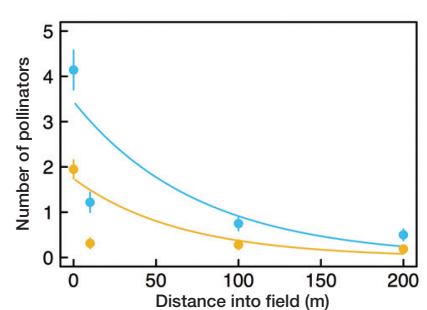

(e)

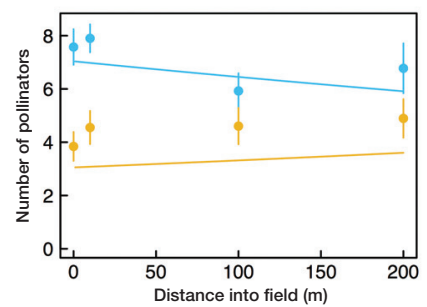

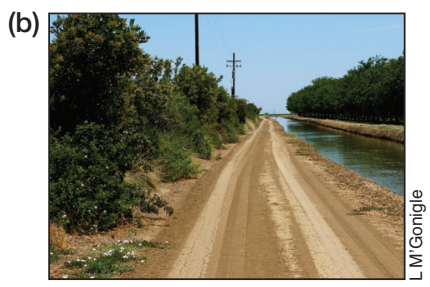

(d)
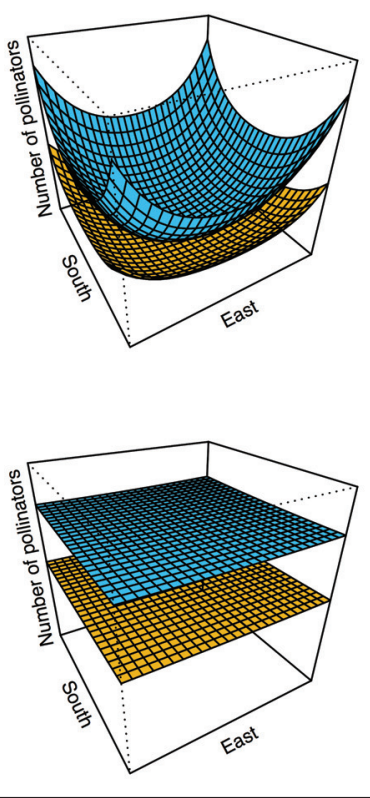

Figure 2. Hedgerows adjacent to crop monocultures enhance wild pollinators in California. Study site (a) before planting in 2007 and (b) 5 years later. (c) Tomato fields next to hedgerows (blue) have more pollinators than those without hedgerows (gold), but pollinator abundance declines with increasing distance from the field edge into the field. (e) Canola attracts pollinators farther into the field. Regression lines with Poisson error distribution are depicted; closed circles and vertical bars indicate means and standard errors, respectively, across sites (Morandin and Kremen 2013). Panels (d) and ( $f$ ) provide a threedimensional, additive extrapolation, with hedgerows on four sides of a field.

changes in the crop species or system (eg organic versus conventional).

Reducing the use of synthetic insecticides that are toxic to pollinating insects should provide an important benefit (Tuell and Isaacs 2010). For example, in South Africa, insecticides adversely affected pollinators, impairing rather than enhancing mango yield (WebTable 1). Insecticides with low toxicity to pollinators, with nondust formulations, applied locally through integrated pest management practices, and applied during the non-flowering season are less likely to be detrimental to pollinators than highly toxic, systemic insecticides that are broadly sprayed from airplanes (Vaughan et al. 2007).

No-tillage farming may enhance populations of groundnesting bees given that many species place their brood cells $<30 \mathrm{~cm}$ below the surface (Roulston and Goodell 2011). Tillage timing, depth, and method probably have 
High diversity of flowering wild plants

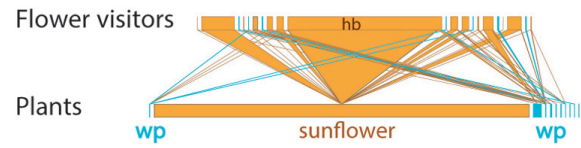

\section{Low diversity of flowering wild plants}
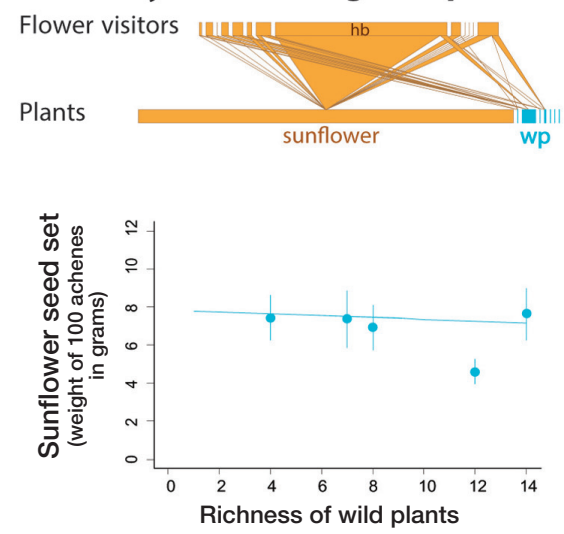
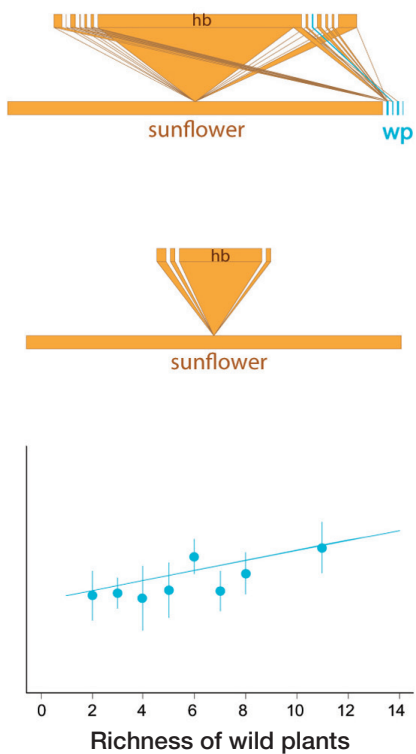
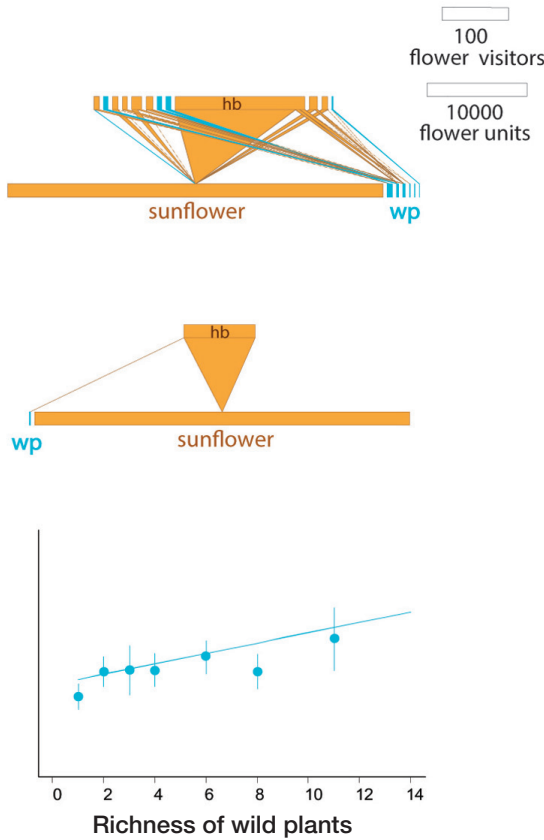

Figure 3. Richness of wild plants (wp) improves sunflower visitation and seed set far from natural areas in South Africa. (top panel) From left to right, flower visitation webs within farms located near (28-108 m), at medium distance (280-652 $\mathrm{m}$ ), or far (683-1120 m) from natural habitat. Sunflower and its flower visitors are in orange ( $h b$ : honey bee), while other species are in blue. Each species is represented by a rectangle, scaled to species abundance. Line widths represent visitation frequency. (bottom panel) Mean \pm standard deviation seed set as a function of plant richness across twenty 4-m $\times 4-m$ plots (Carvalheiro et al. 2011).

differential impacts on pollinators and pollination, but further studies are required to verify this expectation (WebTable 1). Similarly, flood irrigation may be detrimental in comparison to drip irrigation because of the increased likelihood of flooding pollinator nests but, particularly in arid systems, irrigation in general can promote wild-insect abundance through higher productivity of flowering plants or by making the soil easier to excavate (Julier and Roulston 2009).

Enhancing flowering plant richness within crop fields can benefit pollinator richness (Nicholls and Altieri 2013) and crop pollination, as demonstrated for mango (WebTable 1) and sunflower (Figure 3; WebTable 1) in South Africa. Similar results were found for wild plants within watermelon and muskmelon fields in the US (Winfree et al. 2008). In Ghana, banana intercropping with cocoa boosted pollinator (ceratopogonid midge) abundance and cocoa pod set (Frimpong et al. 2011). A diverse set of flower species (crop or non-crop) with different phenologies is likely to increase resource stability for pollinators (Blüthgen and Klein 2011; Mandelik et al. 2012) and thus the resilience of pollination services. Herbicides and mowing can negatively affect pollinators by reducing floral resources provided by weeds (Figure 3), but can be useful for reducing the abundance of invasive grasses that could otherwise displace native flowering plants (Isaacs et al. 2009).

Organic farming combines some of the practices described above and can enhance wild pollinator populations in comparison to conventional farming (Kennedy et al. 2013), probably because of the absence of synthetic insecticides and/or greater non-crop floral resources. Farmland heterogeneity can also be increased by organic management practices, which account for less than $1 \%$ of global agriculture (FAO 2013). When the extent of organic farming was expanded in a German agrolandscape from $5 \%$ to $20 \%$, bee richness rose by $50 \%$, while the density of solitary bees and bumble bees increased by $60 \%$ and 150\%, respectively (Holzschuh et al. 2008). Pollination-related benefits of organic practices were also found for strawberry in Sweden (Andersson et al. 2012) and canola in Canada (Morandin and Winston 2005).

Sowing flowering crops, instead of crops that do not offer floral resources for pollinators, may enhance wild pollinators in heterogeneous landscapes (Holzschuh et al. 2013). In western France, solitary-bee richness and abundance were higher in margins of canola fields than in fields of other crops (Le Féon et al. 2013). In the UK, bumble bee abundance was higher in areas adjacent to bean fields than to wheat fields but only during crop flowering (Hanley et al. 2011), suggesting a short-term behavioral response to flower abundance rather than a long-term population enhancement. Similarly, in Germany, canola improved bumble bee early-colony growth but not whole-season sexual reproduction (Westphal et al. 2009), and greater land cover of mass-flowering crops increased the number of bum- 
ble bee workers but not colony numbers (Herrmann et al. 2007). Therefore, although crops can provide abundant resources, the short duration of floral availability, the low diversity of resources, the application of insecticides, and the presence of tillage may limit the capacity of one crop species to support wild pollinator populations on its own (Vanbergen and the Insect Pollinators Initiative 2013). Furthermore, large monocultures of flowering crops can suffer from pollination deficit and trigger indirect negative effects on pollinators (Figure 1). Sowing crops that bloom in different periods may therefore increase wild-insect populations; in Sweden, bumble bee reproduction was improved in landscapes with both late-season flowering red clover and early-season mass-flowering crops (Rundlöf et al. 2014). Moreover, managing crop phenology (eg through breeding) to better match the availability of efficient pollinators should enhance pollination, but we found no studies on this practice (WebTable 1).

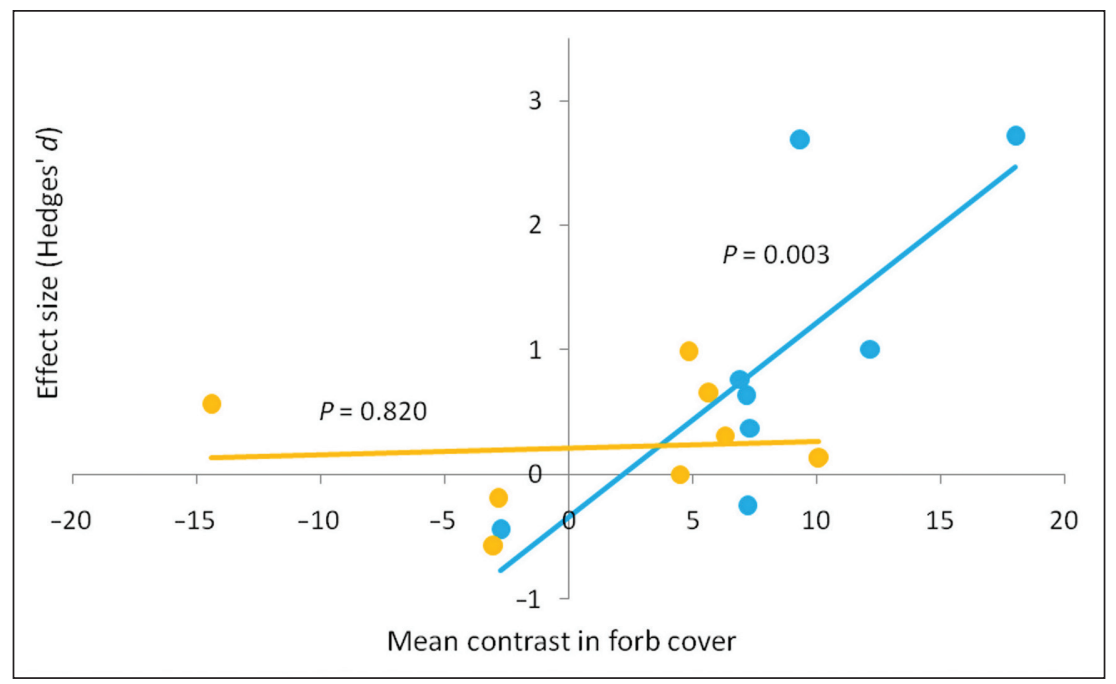

Figure 4. Agri-environmental schemes in Europe enhance bee species richness (d values above zero) in croplands (blue circles) and grasslands (gold circles). The magnitude of this enhancement (effectiveness) increases with the contrast in resource availability (percentage of forb cover) between fields with and without schemes in croplands (blue regression line), but not in grasslands (gold regression line). Effect size for richness indicates Hedges' unbiased weighted standardized mean difference (Hedges' d), which is the difference between environment scheme and control field means corrected by their pooled standard deviation. Regression lines and $\mathrm{P}$ values are shown for meta-regressions (Scheper et al. 2013).

\section{Which practices are more effective in space and time?}

The effectiveness of pollinator-supporting practices is influenced by interactive effects between large (landscape) and small (within-field) scale factors. For example, the effects of landscape composition (the proportion of different habitats) on bee richness are greater on farms with low habitat diversity than on farms with high habitat diversity (Kennedy et al. 2013). Similarly, in Argentina, the importance of wildflower strips as pollinator sources for sunflower increased in the absence of large remnants of natural habitats nearby (Sáez et al. 2012). In South Africa, the importance of weed richness for enhancing sunflower seed set increased with larger distances from natural areas (Figure 3).

Throughout Europe, extensive programs aim to mitigate biodiversity loss on farmland through practices such as organic farming or wildflower strips, thereby offering a unique opportunity to understand interactions among these methods. A meta-analysis showed that these (small-scale) practices enhanced pollinator richness (Figure 4), but their effectiveness varied with (1) the magnitude of increase in flowering plant cover resulting from the practices, (2) farmland type, and (3) landscape context (Scheper et al. 2013). Because intensively managed croplands are generally devoid of flowering plants, pollinator-supporting practices in these landscapes result in the largest increase in floral resources and thus pollinator richness (Figure 4). On the other hand, conventionally managed grasslands generally contain more flowering plant species than arable fields, making it more difficult to enhance floral resources and pollinators (Scheper et al. 2013). Finally, local effects were more positive in structurally simple landscapes (1-20\% semi-natural habitat) than in cleared $(<1 \%$ semi-natural habitat) or complex (>20\% semi-natural habitat) landscapes, presumably because cleared landscapes lack sources of pollinator colonists and complex landscapes have less need of restoration.

Recently, researchers have begun to explore the relative effectiveness of different pollinator-supporting practices. In Europe, flower strips were more effective than grass-sown or naturally regenerated strips (Scheper et al. 2013). Globally, the effect of landscape composition and farm management (within-farm habitat diversity and organic versus conventional) was more important for improving bee richness than the effect of landscape configuration (the arrangement in space and time of different habitats; Kennedy et al. 2013). Interestingly, conventional farms with high in-field habitat diversity maintained similar pollinator abundance as organic farms with low in-field habitat diversity, across the gradient of heterogeneity in surrounding land use. Thus, different combinations of local and landscape practices can result in similar outcomes in terms of promoting pollinator richness, providing alternative solutions suited to different agricultural settings.

The importance of small-scale practices is likely greater for insects with short flight ranges foraging from a fixed nest, such as small- to medium-sized bees, which usually forage within an area of a few hundred meters and comprise the greatest fraction of bee species (Murray et al. 


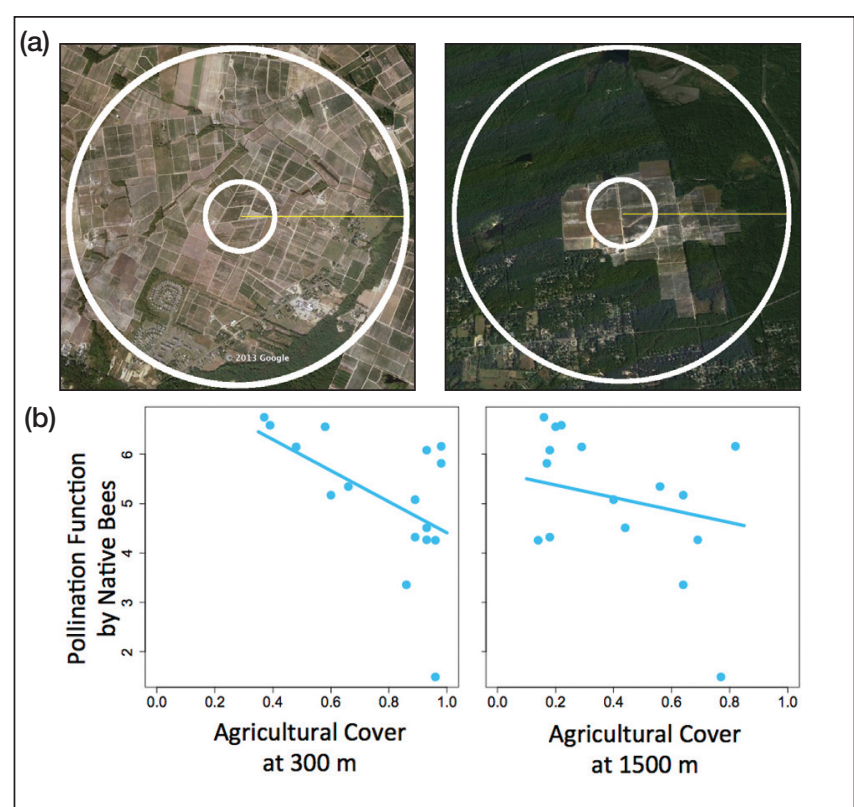

Figure 5. Land use immediately surrounding blueberry fields exerts the strongest effect on pollination services in New Jersey. (a) Study sites were selected so that the proportion of agricultural land cover at the local (300 m, inner circles) and landscape (1500 m, outer circles) scales was uncorrelated across study sites; two representative sites are shown. (b) Land use at the local scale had a stronger effect on pollination services than at the landscape scale. Pollination services are measured as the logtransformed number of blueberry pollen grains deposited on blueberry stigmas by wild pollinators (Benjamin et al. 2014).

2009; Zurbuchen et al. 2010b). Consistent with the idea that small-scale practices alone can have high impact, a study designed to separate the effects of local- versus landscape-scale habitat on pollination services delivered to blueberries found that the local scale had stronger positive effects (Figure 5). Indeed, farmers acting individually are more likely to improve the quality of their own fields and the immediate surroundings than to be able to manage complete landscapes for pollinators. Assuming a foraging range of $200 \mathrm{~m}$ from the nest for small bee species (Zurbuchen et al. 2010b, a), diverse and highquality habitats need to be provided within 13 ha (ie the surface of a 200-m-radius circle).

\section{Costs and benefits of practices}

Understanding the socioeconomic consequences of pollinator-supporting practices is essential to effectively enhancing wild pollinator richness in "real-world" (as opposed to modeled) landscapes (Grieg-Gran and Gemmill-Herren 2012). Farmers generally face implementation costs, such as those for planting hedgerows, and opportunity costs, such as those for setting aside natural habitats that could otherwise be cultivated (Olschewski et al. 2006). Off-field practices have the advantage that land owners do not need to change their typical crop management; however, they still entail implementation and opportunity costs. On the other hand, on-field practices generally necessitate changes in how farmers manage their crops, which may reduce implementation costs (eg lower insecticide use) but potentially increase opportunity costs (eg because of a positive effect of insecticide on crop yield).

Occasionally, the costs of implementing these pollinator-supporting practices are higher than the income derived from their implementation (Olschewski et al. 2006), resulting in a low likelihood of adoption. However, such practices can generate other benefits for society, such as the enhancement of biodiversity; mitigation of soil erosion; and improvements in pest control, nutrient cycling, and/or water use efficiency (Kremen and Miles 2012; Wratten et al. 2012; Shackelford et al. 2013). Many countries have therefore developed governmentsponsored programs (Figure 4; see also the Conservation Reserve Program in the US or Australia's Landcare program) that compensate farmers for enhancing biodiversity and ecosystem services, which are essential for human well-being but have no market value.

In other situations, pollinator-supporting practices are profitable to farmers independent of government payments (Carvalheiro et al. 2012). Some of these practices imply lower costs (eg a more targeted use of herbicides or mowing) or fewer additional costs (eg setting aside a small area in soils with intrinsic limitations where crop yield is low). In the US state of Michigan, plantings of native wildflowers gradually increased wild bee and syrphid abundance as well as blueberry yield in fields adjacent to the plantings, as compared with fields with a standard grassy perimeter (Figure 6). While the cost of establishing the plantings resulted in negative profit in the first year, the gain from pollinatorenhanced yield outpaced the costs of the establishment and maintenance by the fourth year, and growers made cumulative profits (Figure 6). The plantings were on land that could not be cropped with blueberry because of soil or topography limitations, so there was no opportunity cost of "lost" crop production. The perennial wildflower plantings, if properly managed, will likely provide this benefit for many years. Furthermore, such practices have the added benefit of supplying habitat for natural enemies and enhancing biological control of pests in fields adjacent to the plantings. Although economic valuations of pollination services exist (eg Winfree et al. 2011b), studies that consider both the costs and benefits of pollinator-supporting practices are rare (WebTable 1). We highlight the importance of estimating the marginal profits of implementing such practices (Fisher et al. 2008), because management usually only partially increases or decreases ecosystem services (rather than maximizing or eliminating them).

\section{General science-based advice to land managers and policy makers}

Our consensus, based on the reviewed evidence, indicates that: 
- Pollinator richness (and associated aggregate abundance of wild insects) contributes to crop pollination even when honey bees are present in high abundance (Figure 1).

- Pollinator richness increases with the diversity of floral resources (WebTable 1).

- Effectiveness of pollinator-supporting practices (eg flower strips) is context-dependent, and usually more successful in situations where background floral resources are scarce. In cases where abundant floral resources are available, these should be preserved (Figure 4).

- Effectiveness of large-scale practices (eg natural or organic area) varies according to the smaller-scale practices carried out (eg plant diversity within fields), and vice versa (Figure 3). Different combinations of local and landscape practices can result in similar outcomes in terms of promoting pollinator richness, providing alternative solutions suited to different agricultural settings.

- Small-scale practices can have major effects on pollinators and pollination services (Figures 2 and 5). The relative importance of such smaller-scale initiatives is likely greater for pollinators with shorter flight ranges.

- Enhancement of wild pollinators can take several years but still be cost-effective (Figure 6). However, the generality of this conclusion is uncertain and more studies are needed in a variety of crop, landscape, and economic contexts (WebTable 1).

- On the basis of current evidence (WebTable
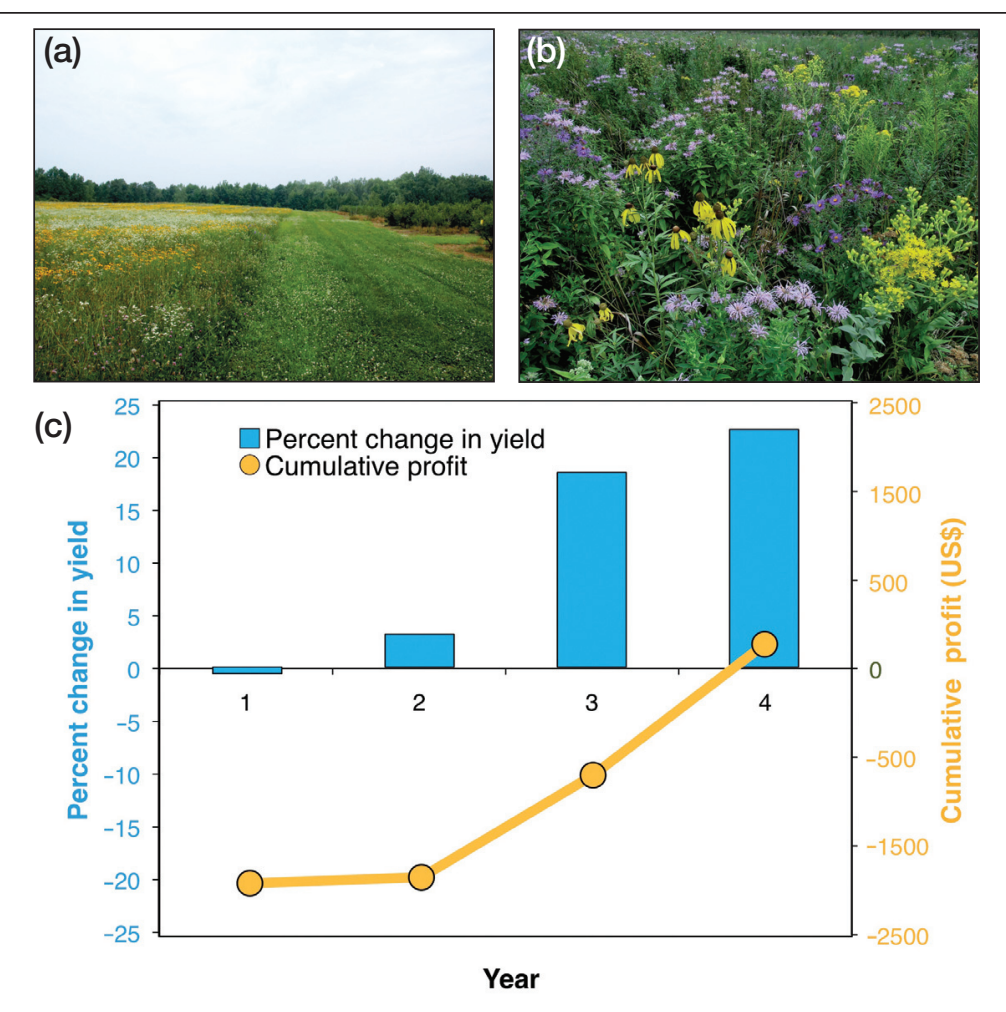

Figure 6. Plantings of native wildflower species selected for support of pollinators enhance blueberry yield and profit in Michigan. (a) Planting in midsummer with blueberry on the right. (b) Close-up of a mature planting with a mix of flower forms, species, and colors, with blueberry in the background. (c) Percent change in blueberry yield (blue bars) between fields adjacent to wildflower plantings and fields without plantings. The gold line (cumulative profit) shows that the initial cost of establishment in the first year was paid for by the fourth year when higher yield resulted in a profit (Blaauw and Isaacs 2014).
1 ), we propose that a practical way to start transforming pollinator-limiting landscapes into more suitable ones is to carry out more targeted use of insecticides, and to employ marginal land to establish and maintain flower strips and hedgerows, as well as to restore (semi-)natural areas adjacent to crops (less than $200 \mathrm{~m}$ away). These changes will also increase farmland heterogeneity, benefiting the sustainability of agriculture.

\section{Conclusions}

Single-species bee management (eg A mellifera, Bombus spp, Osmia spp) is the mainstream approach to crop pollination. Despite providing acceptable yields in some systems, this form of management does not replace the contribution of rich assemblages of wild pollinators (Figure 1), and carries the risks associated with facilitating pathogen, disease, and predator incidence. Therefore, we argue for integrated management of single species and wild pollinator assemblages (WebTable 1; WebFigure 1). Indeed, practices that enhance wild pollinators will likely also increase resources for managed species and help to sustain, for instance, honey bee colony health.
Promotion of biodiversity within agricultural landscapes is essential for sustaining associated ecosystem services. This paper provides a general framework to enhance wild insects and associated pollination services, which resource managers and policy makers can adapt to specific landscape conditions, crop varieties, and crop management strategies. These practices will have additional benefits to crop pollination, including the enhancement of scenic values, cultural values, plant and insect diversity, and other ecosystem services. Transdisciplinary work is essential to implement pollinator-supporting practices in real-world landscapes and support longterm yields of pollinator-dependent crops.

\section{Acknowledgements}

F Benjamin, I Bartomeus, B Gemmill-Herren, and CL Morales provided insightful comments that improved the manuscript. The authors declare no competing financial interests. This research was funded by Universidad Nacional de Río Negro (PI 40-B-259), EU FP7 project "Status and Trends of European Pollinators" (244090, www.STEP-project.net), EU FP7 project "Securing the 
Conservation of biodiversity across Administrative Levels and spatial, temporal, and Ecological Scales" (www.scales-project.net), and the US Department of Agriculture's Sustainable Agriculture Research and Education program.

\section{References}

Aizen MA and Harder LD. 2009. The global stock of domesticated honey bees is growing slower than agricultural demand for pollination. Curr Biol 19: 915-18.

Albrecht M, Schmid B, Hautier Y, and Müller CB. 2012. Diverse pollinator communities enhance plant reproductive success. $P$ Roy Soc B-Biol Sci 279: 4845-52.

Andersson GKS, Rundlöf M, and Smith HG. 2012. Organic farming improves pollination success in strawberries. PLoS ONE 7: $2-5$.

Benjamin FE, Reilly JR, and Winfree R. 2014. Pollinator body size mediates the scale at which land use drives crop pollination services. J Appl Ecol 51: 440-49.

Blaauw BR and Isaacs R. 2014. Flower plantings increase wild bee abundance and the pollination services provided to a pollination-dependent crop. J Appl Ecol 51: 890-98.

Blüthgen N and Klein AM. 2011. Functional complementarity and specialisation: the role of biodiversity in plant-pollinator interactions. Basic Appl Ecol 12: 282-91.

Bohart GE. 1972. Management of wild bees for the pollination of crops. Annu Rev Ecol Evol S 17: 287-312.

Brittain C, Kremen C, and Klein AM. 2013. Biodiversity buffers pollination from changes in environmental conditions. Glob Change Biol 19: 540-47.

Carvalheiro LG, Seymour CL, Nicolson SW, and Veldtman R. 2012. Creating patches of native flowers facilitates crop pollination in large agricultural fields: mango as a case study. J Appl Ecol 49: 1373-83.

Carvalheiro LG, Veldtman R, Shenkute AG, et al. 2011. Natural and within-farmland biodiversity enhances crop productivity. Ecol Lett 14: 251-59.

FAO (UN Food and Agriculture Organization). 2008. Tools for conservation and use of pollination services: initial survey of good pollination practices. Rome, Italy: FAO.

FAO (UN Food and Agriculture Organization). 2013. FAOSTAT http://faostat.fao.org/site/377/default.aspx\#ancor. Viewed 05 Oct 2013.

Fisher B, Turner K, Zylstra M, et al. 2008. Ecosystem services and economic theory: integration for policy-relevant research. Ecol Appl 18: 2050-67.

Fontaine C, Dajoz I, Meriguet J, and Loreau M. 2006. Functional diversity of plant-pollinator interaction webs enhances the persistence of plant communities. PLoS Biol 4: e1.

Frimpong EA, Gemmill-Herren B, Gordon I, and Kwapong PK. 2011. Dynamics of insect pollinators as influenced by cocoa production systems in Ghana. J Pollination Ecol 5: 74-80.

Garibaldi LA, Aizen MA, Klein AM, et al. 2011a. Global growth and stability of agricultural yield decrease with pollinator dependence. P Natl Acad Sci USA 108: 5909-14.

Garibaldi LA, Steffan-Dewenter I, Kremen C, et al. 2011b. Stability of pollination services decreases with isolation from natural areas despite honey bee visits. Ecol Lett 14: 1062-72.

Garibaldi LA, Steffan-Dewenter I, Winfree R, et al. 2013. Wild pollinators enhance fruit set of crops regardless of honey bee abundance. Science 339: 1608-11.

Grieg-Gran M and Gemmill-Herren B. 2012. Handbook for participatory socioeconomic evaluation of pollinator-friendly practices. Rome, Italy: FAO.

Hanley ME, Franco M, Dean CE, et al. 2011. Increased bumblebee abundance along the margins of a mass flowering crop: evidence for pollinator spill-over. Oikos 120: 1618-24.
Herrmann F, Westphal C, Moritz RFA, and Steffan-Dewenter I. 2007. Genetic diversity and mass resources promote colony size and forager densities of a social bee (Bombus pascuorum) in agricultural landscapes. Mol Ecol 16: 1167-78.

Hoehn P, Tscharntke T, Tylianakis JM, and Steffan-Dewenter I. 2008. Functional group diversity of bee pollinators increases crop yield. P Roy Soc B-Biol Sci 275: 2283-91.

Holzschuh A, Dormann CF, Tscharntke T, and Steffan-Dewenter I. 2013. Mass-flowering crops enhance wild bee abundance. Oecologia 172: 477-84.

Holzschuh A, Steffan-Dewenter I, and Tscharntke T. 2008. Agricultural landscapes with organic crops support higher pollinator diversity. Oikos 117: 354-61.

Isaacs R, Tuell J, Fiedler A, et al. 2009. Maximizing arthropodmediated ecosystem services in agricultural landscapes: the role of native plants. Front Ecol Environ 7: 196-203.

Julier HE and Roulston TH. 2009. Wild bee abundance and pollination service in cultivated pumpkins: farm management, nesting behavior and landscape effects. J Econ Entomol 102: 563-73.

Kennedy CM, Lonsdorf E, Neel MC, et al. 2013. A global quantitative synthesis of local and landscape effects on wild bee pollinators in agroecosystems. Ecol Lett 16: 584-99.

Kremen C and Miles A. 2012. Ecosystem services in biologically diversified versus conventional farming systems: benefits, externalities, and trade-offs. Ecol Soc 17: 40.

Kremen C, Williams NM, Aizen MA, et al. 2007. Pollination and other ecosystem services produced by mobile organisms: a conceptual framework for the effects of land-use change. Ecol Lett 10: 299-314.

Le Féon V, Burel F, Chifflet R, et al. 2013. Solitary bee abundance and species richness in dynamic agricultural landscapes. Agr Ecosyst Environ 166: 94-101.

Mandelik Y, Winfree R, Neeson T, and Kremen C. 2012. Complementary habitat use by wild bees in agro-natural landscapes. Ecol Appl 22: 1535-46.

Menz MHM, Phillips RD, Winfree R, et al. 2011. Reconnecting plants and pollinators: challenges in the restoration of pollination mutualisms. Trends Plant Sci 16: 4-12.

Morandin LA and Kremen C. 2013. Hedgerow restoration promotes pollinator populations and exports native bees to adjacent fields. Ecol Appl 23: 829-39.

Morandin LA and Winston ML. 2005. Wild bee abundance and seed production in conventional, organic, and genetically modified canola. Ecol Appl 15: 871-81.

Murray TE, Kuhlmann M, and Potts SG. 2009. Conservation ecology of bees: populations, species and communities. Apidologie 40: 211-36.

Nicholls CI and Altieri MA. 2013. Plant biodiversity enhances bees and other insect pollinators in agroecosystems. A review. Agron Sustain Dev 33: 257-74.

Olschewski R, Tscharntke T, Benitez PC, et al. 2006. Economic evaluation of pollination services comparing coffee landscapes in Ecuador and Indonesia. Ecol Soc 11: 7.

Roulston TH and Goodell K. 2011. The role of resources and risks in regulating wild bee populations. Annu Rev Entomol 56: 293-312.

Rundlöf M, Persson AS, Smith HG, and Bommarco R. 2014. Lateseason mass-flowering red clover increases bumble bee queen and male densities. Biol Conserv 172: 138-45.

Sáez A, Sabatino M, and Aizen MA. 2012. Interactive effects of large- and small-scale sources of feral honey-bees for sunflower in the Argentine Pampas. PLoS ONE 7: e30968.

Scheper J, Holzschuh A, Kuussaari M, et al. 2013. Environmental factors driving the effectiveness of European agri-environmental measures in mitigating pollinator loss - a meta-analysis. Ecol Lett 16: 912-20.

Shackelford G, Steward PR, Benton TG, et al. 2013. Comparison of pollinators and natural enemies: a meta-analysis of landscape 
and local effects on abundance and richness in crops. Biol Rev Camb Philos 88: 1002-21.

Steffan-Dewenter I and Schiele S. 2008. Do resources or natural enemies drive bee population dynamics in fragmented habitats? Ecology 89: 1375-87.

Tuell JK and Isaacs R. 2010. Community and species-specific responses of wild bees to insect pest control programs applied to a pollinator-dependent crop. J Econ Entomol 103: 668-75.

Vanbergen AJ and the Insect Pollinators Initiative. 2013. Threats to an ecosystem service: pressures on pollinators. Front Ecol Environ 11: 251-59.

Vaughan M, Shepherd M, Kremen C, and Black SH. 2007. Farming for bees: guidelines for providing native bee habitat on farms. Portland, OR: The Xerces Society for Invertebrate Conservation.

Waser NM, Chittka L, Price MV, et al. 1996. Generalization in pollination systems, and why it matters. Ecology 77: 1043-60.

Westphal C, Steffan-Dewenter I, and Tscharntke T. 2009. Mass flowering oilseed rape improves early colony growth but not sexual reproduction of bumblebees. J Appl Ecol 46: 187-93.

Williams NM, Crone EE, Roulston TH, et al. 2010. Ecological and life-history traits predict bee species responses to environmental disturbances. Biol Conserv 143: 2280-91.

Winfree R, Aguilar R, Vázquez DP, et al. 2009. A meta-analysis of bees' responses to anthropogenic disturbance. Ecology 90: 2068-76.

Winfree R, Bartomeus I, and Cariveau DP. 2011a. Native pollinators in anthropogenic habitats. Annu Rev Ecol Evol S 42: 1-22.

Winfree R, Gross BJ, and Kremen C. 2011b. Valuing pollination services to agriculture. Ecol Econ 71: 80-88.

Winfree R, Williams NM, Gaines H, et al. 2008. Wild bee pollina- tors provide the majority of crop visitation across land-use gradients in New Jersey and Pennsylvania, USA. J Appl Ecol 45: 793-802.

Wratten SD, Gillespie M, Decourtye A, et al. 2012. Pollinator habitat enhancement: benefits to other ecosystem services. Agr Ecosyst Environ 159: 112-22.

Zurbuchen A, Cheesman S, Klaiber J, et al. 2010a. Long foraging distances impose high costs on offspring production in solitary bees. J Anim Ecol 79: 674-81.

Zurbuchen A, Landert L, Klaiber J, et al. 2010b. Maximum foraging ranges in solitary bees: only few individuals have the capability to cover long foraging distances. Biol Conserv 143: 669-76.

${ }^{4}$ Department of Tropical Biology and Animal Ecology, University of Würzburg, Würzburg, Germany; ${ }^{5}$ Laboratorio Ecotono, INIBIOMA, Universidad Nacional del Comahue-CONICET, Río Negro, Argentina; ${ }^{6}$ Department of Entomology, Michigan State University, East Lansing, MI; ${ }^{7}$ Department of Life Sciences, Terrestrial Invertebrates Division, Natural History Museum, London, UK; ${ }^{8}$ Alterra, Animal Ecology Team, Wageningen, The Netherlands; ${ }^{9}$ Resource Ecology Group, Wageningen University, Wageningen, The Netherlands; ${ }^{10}$ Chair of Nature Conservation and Landscape Ecology, Faculty of Environment and Natural Resources, University of Freiburg, Freiburg, Germany; ${ }^{11}$ Environmental Sciences Policy and Management, University of California - Berkeley, Berkeley, CA; ${ }^{12}$ Department of Ecology, Evolution and Natural Resources, Rutgers University, New Brunswick, NJ 